\title{
Maximum human objectively measured pharmacologically stimulated accommodative amplitude
}

This article was published in the following Dove Press journal:

Clinical Ophthalmology

\author{
Andrzej Grzybowski ${ }^{1,2}$ \\ Ronald A Schachar ${ }^{3}$ \\ Magdalena Gaca-Wysocka ${ }^{2}$ \\ Ira H Schachar ${ }^{4}$ \\ Barbara K Pierscionek ${ }^{5}$ \\ Institute for Research in \\ Ophthalmology, Foundation for \\ Ophthalmology Development, Poznan, \\ ${ }^{2}$ Department of Ophthalmology, \\ University of Warmia and Mazury, \\ Olsztyn, Poland; ${ }^{3}$ Department \\ of Physics, University of Texas, \\ Arlington, TX, ${ }^{4}$ Byers Eye Institute \\ of Stanford University, Palo Alto, \\ CA, USA; ${ }^{5}$ School of Science and \\ Technology, Nottingham Trent \\ University, Nottingham, UK
}

Correspondence: Ronald A Schachar Department of Physics, University of Texas at Arlington, PO Box 8669, La Jolla, CA 92038, USA

Tel +l 858784 I705

Fax + I 2129737132

Email ron@2ras.com
Purpose: To measure the maximum, objectively measured, accommodative amplitude, produced by pharmacologic stimulation.

Methods: Thirty-seven healthy subjects were enrolled, with a mean age of $20.2 \pm 1.1$ years, corrected visual acuity of 20/20, and mean spherical equivalent refraction (SER) $=-0.83 \pm 1.60$ diopters. For each subject, the right pupil was dilated with phenylephrine $10 \%$. After 30 minutes, the pupil was measured, the left eye was patched, and the right eye was autorefracted. Pilocarpine $4 \%$ was then instilled in the right eye, followed by phenylephrine. At 45 minutes after the pilocarpine, autorefraction and pupil size were again measured.

Results: Mean pupil size pre- and postpilocarpine was $8.0 \pm 0.8 \mathrm{~mm}$ and $4.4 \pm 1.9 \mathrm{~mm}$, respectively. Pre- and postpilocarpine, the mean SER was $-0.83 \pm 1.60$ and $-10.55 \pm 4.26$ diopters, respectively. The mean pilocarpine-induced accommodative amplitude was $9.73 \pm 3.64$ diopters. Five subjects had accommodative amplitudes $\geq 14.00$ diopters. Accommodative amplitude was not significantly related to baseline SER ( $p$-value $=0.24$ ), pre- or postpilocarpine pupil size ( $p$-values $=0.13$ and 0.74$)$, or change in pupil size $(p$-value $=0.37)$. Iris color did not statistically significantly affect accommodative amplitude ( $p$-value $=0.83$ ).

Conclusion: Following topically applied pilocarpine, the induced objectively measured accommodation in the young eye is greater than or equal to the reported subjectively measured voluntary maximum accommodative amplitude.

Keywords: maximum, accommodative amplitude, objective, pilocarpine

\section{Introduction}

Using the subjective push-up technique, Duane ${ }^{1}$ demonstrated that accommodative amplitude declines with age and that the amplitudes for a given age had a wide variability. For example, for a 20 year old, Duane ${ }^{1}$ reported lower, mean, usual upper, and extreme upper limits for accommodative amplitude of 9.7, 11.5, 13.0, and 14.0 diopters, respectively. However, the reported, objectively measured, voluntary accommodative amplitude for this same age group, when assessed by dynamic retinoscopy ${ }^{2}$ and autorefraction, ${ }^{3,4}$ had significantly lower means and less variability. Using these methods, the maximum mean accommodative amplitudes were $7.31 \pm 0.77$ diopters ${ }^{2}$ and $6.25 \pm 1.13$ diopters, ${ }^{3}$ respectively. It was also reported that following one drop of pilocarpine $6 \%$ stimulated accommodation, the mean objectively measured mean accommodative amplitude for this age group was 5.05 \pm 3.05 diopters. ${ }^{5}$

Based upon these studies, it has been suggested that the maximum accommodative amplitude for the eye peaks and/or plateaus at approximately 8 diopters. ${ }^{4}$ To evaluate the upper limit of accommodative amplitude in young adults, we objectively measured 
the change in refraction with an autorefractor following topical administration of pilocarpine.

\section{Methods}

\section{Subjects}

To be included in this cohort study, the subjects had to be aged $\geq 18$ years and $\leq 24$ years. Each had to execute an informed consent and have a normal ophthalmological examination with best-corrected visual acuity of 20/20 in the right eye with spherical equivalent refractive error between -5.00 diopters and +2.50 diopters. All methods adhered to the Tenets of the Declaration of Helsinki and the Health Insurance Portability and Accountability Act and were approved by the institutional review board at the Wielkopolska Medical Chamber, Poznan, Poland. Written informed consent was obtained from all participants.

Preliminary testing was performed to design the protocol for the frequency of administration of phenylephrine $10 \%$, which has no effect on accommodative amplitude, ${ }^{6}$ and pilocarpine $4 \%$ required to maximize refractive change while minimizing miosis. Phenylephrine $10 \%$ was instilled in the right eye every minute for five applications. Thirty minutes later, using the right eye, the subject fixated on a nonaccommodative target within an autorefractor and the refraction and pupil size were measured. Pilocarpine 4\%, 1 drop every minute three times, was placed in the right eye. Five minutes later, phenylephrine $10 \%, 1$ drop every minute five times, was also placed in the right eye. Forty-five minutes later, autorefraction and pupil size measurements of the right eye were obtained. The left eye of the subject was patched, and the overall illumination of the examining room was kept constant during all measurements.

\section{Autorefraction, keratometry, and pupil size}

The auto-keratorefractometer (KR8100A; Topcon Medical Systems, Oakland, NJ, USA) enabled keratometric measurements (33.75-67.50 diopters) and closed-view refractive measurements ( -25 to 22 diopters) through a pupil $\geq 2 \mathrm{~mm}$. This model autorefractor has been used as a standard for comparing other refracting techniques and has an accuracy of approximately 0.25 diopters. ${ }^{7}$ The average of three refractions of the right eye of all subjects was measured with the autorefractor pre- and postpilocarpine instillation. The postpilocarpine change in refraction was defined as the change in accommodative amplitude. ${ }^{5}$ Using an IOLMaster 700 (Zeiss IOLMaster 700; Carl Zeiss Meditec AG, Jena, Germany), the pupils were measured three times pre- and postpilocarpine within approximately 1 minute after the autorefraction.

\section{Analysis}

Descriptive statistics and linear regression were performed to assess the association of accommodative amplitude to prepilocarpine spherical equivalent refraction (SER), change in pupil size, and pre- and postpilocarpine pupil size. A box plot and a general linear model with univariate analysis of variance were performed to evaluate the effect of iris color (IC) on accommodative amplitude (IBM SSPS Statistics, Version 24; IBM Corporation, Armonk, NY, USA).

\section{Results}

Thirty-seven subjects were enrolled in the study, with a mean \pm standard deviation age of $20.2 \pm 1.1$ years and a mean prepilocarpine SER of $-0.83 \pm 1.60$ diopters. The color of the subjects' irises (n) were blue (10), green (12), hazel (4), and brown (11). The mean pupil size pre- and postpilocarpine was $8.0 \pm 0.8 \mathrm{~mm}$ and $4.4 \pm 1.9 \mathrm{~mm}$, respectively. The mean SER postpilocarpine was $-10.55 \pm 4.26$ diopters. The mean accommodative amplitude was $9.73 \pm 3.64$ diopters.

Five of the subjects had accommodative amplitudes $\geq 14.00$ diopters. Two of these subjects had brown IC. The prepilocarpine mean keratometry (average of the steep and flat meridians) and refractive cylinder were $43.37 \pm 1.92$ diopters and $0.61 \pm 0.51$ diopters, respectively. The postpilocarpine mean keratometry and refractive cylinder were $43.15 \pm 1.58$ diopters and $0.82 \pm 0.55$ diopters, respectively (Table 1). Using linear regression, accommodative amplitude was not statistically significantly related to baseline SER $\left(r^{2}=0.04, p\right.$-value $\left.=0.24\right)$, pre- or postpilocarpine pupil size $\left(r^{2}=0.07\right.$ and $<0.01, p$-values $=0.13$ and 0.74 , respectively), or change in pupil size $\left(r^{2}=0.02, p\right.$-value $\left.=0.37\right)$. The mean accommodative amplitude for subjects with blue (10), green (12), hazel (4), and brown (11) irises was 10.03 (95\% CI: 7.54-12.19), 10.15 (95\% CI: 8.08-12.01), 10.14 (95\% CI: $4.94-13.12)$, and 8.84 diopters (95\% CI: 6.64-11.12; Figure 1). From the general linear model, there was no statistically significant correlation between IC and amplitude of accommodation $\left(r^{2}=0.03, p\right.$-value $=0.83$ ).

In addition, green, hazel, and brown irises were pooled as dark when compared to blue irises (Figure 2). The mean accommodative amplitude for subjects with blue and dark irises was 10.03 (95\% CI: 7.36-12.69) and 9.815 diopters (95\% CI: 8.16-11.07), respectively. There was no statistical correlation between blue or dark IC and accommodative amplitude $\left(r^{2}<0.01, p\right.$-value $\left.=0.77\right)$.

\section{Discussion}

The objectively measured, pilocarpine stimulated, mean accommodative amplitude for the subjects of this study 
Table I Age, IC, pre- and postpilocarpine mean keratometry, SER, refractive cylinder, pupil size, and accommodative amplitude

\begin{tabular}{|c|c|c|c|c|c|c|c|c|c|c|c|}
\hline \multirow[t]{2}{*}{ Subject } & \multirow[t]{2}{*}{ IC } & \multirow{2}{*}{$\begin{array}{l}\text { Age } \\
\text { (years) }\end{array}$} & \multicolumn{4}{|c|}{ Prepilocarpine } & \multicolumn{5}{|c|}{ Postpilocarpine } \\
\hline & & & $\begin{array}{l}\text { Mean K } \\
\text { (diopters) }\end{array}$ & $\begin{array}{l}\text { SER } \\
\text { (diopters) }\end{array}$ & $\begin{array}{l}\text { Cyl } \\
\text { (diopters) }\end{array}$ & $\begin{array}{l}\text { Pupil } \\
\text { (mm) }\end{array}$ & $\begin{array}{l}\text { Mean K } \\
\text { (diopters) }\end{array}$ & $\begin{array}{l}\text { SER } \\
\text { (diopters) }\end{array}$ & $\begin{array}{l}\text { Cyl } \\
\text { (diopters) }\end{array}$ & $\begin{array}{l}\text { Pupil } \\
\text { (mm) }\end{array}$ & $\begin{array}{l}\text { AA } \\
\text { (diopters) }\end{array}$ \\
\hline I & Brown & 24 & 43.87 & -0.12 & 0.62 & 8.1 & 43.50 & -10.25 & 0.87 & 3.4 & 10.13 \\
\hline 2 & Blue & 20 & 45.62 & 0.00 & 1.12 & 6.6 & 45.50 & -9.25 & 0.75 & 3.0 & 9.25 \\
\hline 3 & Green & 19 & 43.25 & -0.37 & 0.25 & 7.2 & 43.50 & -9.62 & 1.12 & 3.8 & 9.25 \\
\hline 4 & Brown & 19 & 41.25 & -0.62 & 0.12 & 9.1 & 41.12 & -4.37 & 0.25 & 3.2 & 3.75 \\
\hline 5 & Blue & 20 & 44.00 & 1.50 & 1.25 & 7.0 & 43.37 & -9.75 & 0.50 & 7.2 & 11.25 \\
\hline 6 & Blue & 20 & 42.37 & -0.62 & 0.25 & 8.2 & 45.75 & -16.00 & 0.75 & 7.4 & 15.38 \\
\hline 7 & Hazel & 20 & 39.50 & 1.37 & 0.37 & 8.2 & 40.37 & -8.37 & 0.37 & 3.2 & 9.74 \\
\hline 8 & Blue & 19 & 42.12 & -0.75 & 0.75 & 7.6 & 42.25 & -5.12 & 0.50 & 7.0 & 4.37 \\
\hline 9 & Green & 20 & 47.37 & -4.25 & 1.00 & 7.7 & 44.00 & -14.75 & 1.25 & 7.6 & 10.50 \\
\hline 10 & Blue & 20 & 47.25 & -0.62 & 0.25 & 6.6 & 43.87 & -5.50 & 0.87 & 6.3 & 4.88 \\
\hline II & Hazel & 20 & 43.50 & -0.75 & 0.87 & 8.2 & 43.25 & -13.87 & 0.37 & 4.8 & 13.12 \\
\hline 12 & Green & 20 & 42.87 & -0.37 & 0.37 & 8.6 & 42.25 & -17.25 & 0.37 & 6.4 & 16.88 \\
\hline 13 & Brown & 19 & 44.87 & -1.25 & 0.50 & 8.7 & 44.87 & -4.75 & 0.50 & 6.2 & 3.50 \\
\hline 14 & Blue & 19 & 44.25 & 0.25 & 1.00 & 8.9 & 44.00 & -13.37 & 1.75 & 6.9 & 13.62 \\
\hline 15 & Hazel & 19 & 40.62 & 0.75 & 0.50 & 8.4 & 40.62 & -4.19 & 0.37 & 5.8 & 4.94 \\
\hline 16 & Green & 19 & 43.00 & 0.12 & 0.12 & 7.8 & 43.00 & -4.31 & 0.12 & 7.6 & 4.43 \\
\hline 17 & Green & 19 & 44.62 & -0.37 & 3.00 & 6.6 & 44.37 & -3.87 & 2.87 & 3.7 & 3.50 \\
\hline 18 & Brown & 22 & 42.37 & -3.12 & 0.62 & 8.9 & 42.37 & -19.37 & 1.37 & 6.5 & 16.25 \\
\hline 19 & Brown & 22 & 42.75 & -1.25 & 0.25 & 7.6 & 43.62 & -9.75 & 1.37 & 6.2 & 8.50 \\
\hline 20 & Brown & 19 & 42.87 & 1.62 & 0.75 & 5.6 & 42.75 & -5.75 & 0.87 & 3.4 & 7.37 \\
\hline 21 & Blue & 20 & 45.50 & -1.37 & 0.62 & 8.6 & 45.00 & -9.12 & 0.50 & 7.6 & 7.75 \\
\hline 22 & Green & 20 & 41.12 & 0.12 & 0.50 & 8.0 & 41.00 & -10.62 & 0.50 & 4.5 & 10.74 \\
\hline 23 & Green & 20 & 43.12 & -0.62 & 0.37 & 8.1 & 43.00 & -13.12 & 1.12 & 3.0 & 12.50 \\
\hline 24 & Green & 21 & 45.25 & -0.37 & 0.75 & 8.7 & 44.62 & -10.62 & 1.62 & 2.4 & 10.25 \\
\hline 25 & Brown & 21 & 44.00 & -4.25 & 0.50 & 8.8 & 44.00 & -14.50 & 0.75 & 2.7 & 10.25 \\
\hline 26 & Brown & 19 & 44.75 & -2.75 & 0.25 & 8.0 & 44.00 & -17.00 & 1.25 & 2.7 & 14.25 \\
\hline 27 & Green & 19 & 41.75 & 0.00 & 0.00 & 8.7 & 41.50 & -9.50 & 0.50 & 3.4 & 9.50 \\
\hline 28 & Blue & 20 & 44.00 & 0.00 & 0.50 & 8.4 & 42.00 & -14.00 & 1.50 & 2.6 & 14.00 \\
\hline 29 & Blue & 21 & 45.25 & 0.25 & 0.50 & 8.3 & 45.00 & -8.75 & 0.75 & 2.8 & 9.00 \\
\hline 30 & Green & 20 & 42.25 & -4.25 & 1.00 & 7.8 & 42.75 & -16.50 & 0.25 & 2.9 & 12.25 \\
\hline 31 & Brown & 21 & 41.00 & -1.50 & 0.50 & 7.0 & 41.00 & -12.00 & 0.50 & 2.9 & 10.50 \\
\hline 32 & Brown & 21 & 46.00 & -0.25 & 0.75 & 7.8 & 46.00 & -6.00 & 1.00 & 2.7 & 5.75 \\
\hline 33 & Green & 21 & 42.50 & -1.00 & 0.50 & 7.4 & 42.25 & -11.50 & 0.25 & 3.6 & 10.50 \\
\hline 34 & Hazel & 21 & 43.75 & -1.00 & 0.50 & 8.0 & 43.25 & -13.75 & 0.75 & 2.3 & 12.75 \\
\hline 35 & Brown & 21 & 42.25 & -1.25 & 0.75 & 8.9 & 42.75 & -8.25 & 0.50 & 2.8 & 7.00 \\
\hline 36 & Green & 21 & 39.50 & 1.25 & 0.00 & 9.3 & 39.70 & -10.25 & 0.75 & 3.1 & 11.50 \\
\hline \multirow[t]{4}{*}{37} & Blue & 21 & 45.00 & -4.75 & 0.75 & 8.7 & 44.75 & -15.50 & 0.75 & 2.3 & 10.75 \\
\hline & Mean & 20.2 & 43.37 & -0.83 & 0.61 & 8.0 & 43.15 & -10.55 & 0.82 & 4.4 & 9.73 \\
\hline & SD & I.I & 1.92 & 1.60 & 0.51 & 0.8 & 1.58 & 4.26 & 0.55 & 1.9 & 3.64 \\
\hline & Median & 20.0 & 43.25 & -0.62 & 0.50 & 8.1 & 43.25 & -10.25 & 0.75 & 3.4 & 10.25 \\
\hline
\end{tabular}

Abbreviations: IC, iris color; K, keratometry; SER, spherical equivalent refraction; Cyl, refractive cylinder; AA, accommodative amplitude.

was 9.73 diopters. Eleven subjects had accommodative amplitudes $\geq 11.5$ diopters, of whom five subjects had accommodative amplitudes $\geq 14.00$ diopters. Although these measurements exceed the accommodative amplitudes reported in the modern literature, ${ }^{2-5}$ these measurements correspond to the lower limit, mean, and extreme upper limit of Duane's push-up measurements for 20-year-old subjects. ${ }^{1}$ Following pilocarpine topical administration, the subjects in this study were capable of accommodating equal to or more than the reported subjective push-up measurement of voluntary accommodation for their age. A similar large accommodative response to pilocarpine was reported in healthy $25-29$ year old subjects. ${ }^{8}$

To prevent poor autorefractive measurements, the effect of pupillary constriction from pilocarpine was mitigated by pretreatment with phenylephrine. As a result, pupil size was on average $4.4 \mathrm{~mm}$, which was more than sufficient to obtain reliable autorefractions. When using this methodology, pupil 


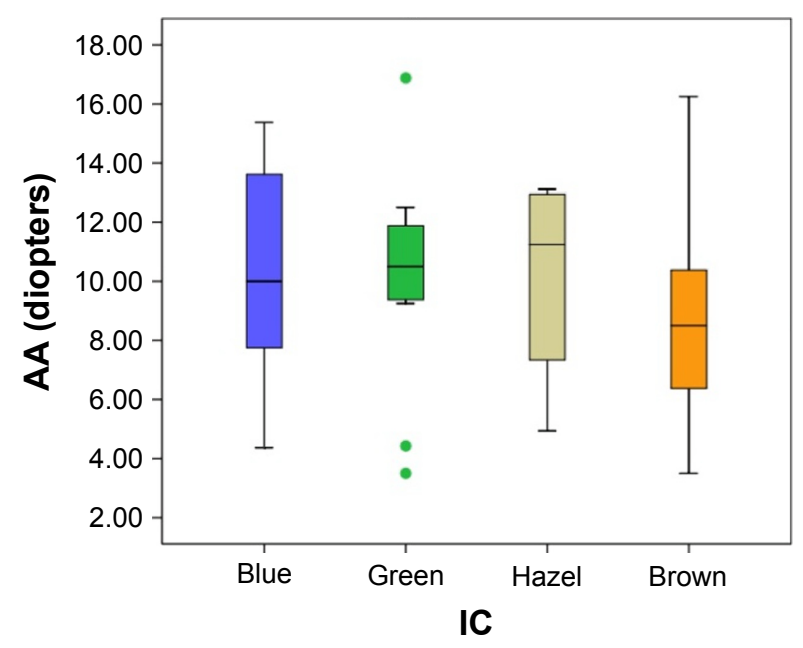

Figure I Box plot of accommodative amplitude versus iris color showing the medians and $25 \%$ and $75 \%$ quartiles.

Abbreviations: AA, accommodative amplitude; IC, iris color.

size was not statistically associated with accommodative amplitude. Consistent with the reported lack of change of corneal topography ${ }^{9,10}$ and lenticular astigmatism ${ }^{11}$ during accommodation, the mean change for both keratometry and refractive cylinder in this study was less than the repeatability of the autorefractor, ie, $<0.25$ diopters. Although baseline subjective accommodative amplitude was not measured, it is unlikely that in the young healthy study subjects baseline push-up accommodative amplitude would have significantly differed from that reported by Duane, ${ }^{1,12}$ or that the magnitude of their subjective accommodation would have affected their autorefractor measured response to pilocarpine..$^{5,13}$

One potential source of error is the variability of pilocarpine-induced ciliary muscle constriction in our

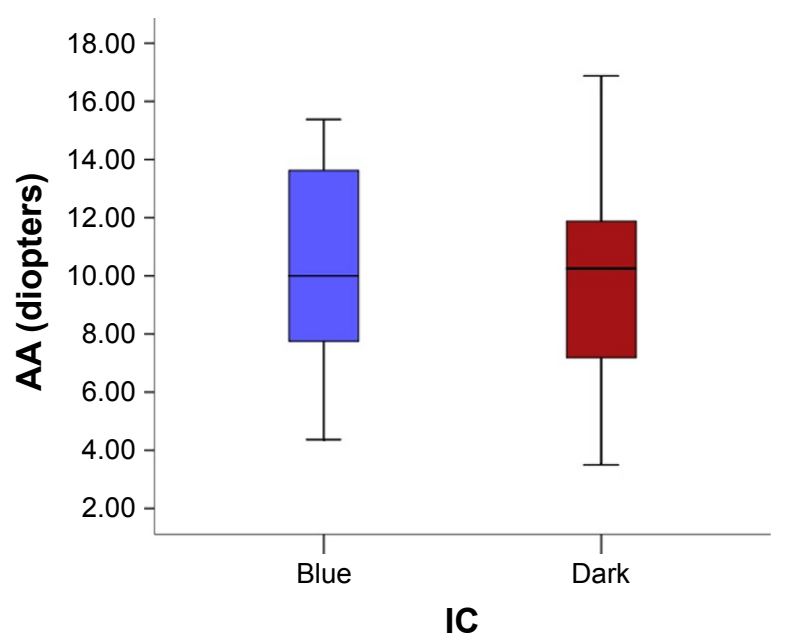

Figure 2 Box plot of accommodative amplitude versus blue and dark iris color showing the medians and $25 \%$ and $75 \%$ quartiles.

Abbreviations: AA, accommodative amplitude; IC, iris color. subject population. There are a number of reasons that possibly explain this high degree of variation. Pilocarpine is bound and inactivated by melanin. ${ }^{14}$ Therefore, pigmented eyes containing higher amounts of melanin may experience less of a pharmacologic effect. In this study, IC did not have a statistically significant effect on accommodative amplitude; however, there was a large variation in accommodative amplitude in subjects with the same color iris (Figure 1). This large variation may be due to differing rates of pilocarpine absorption through the cornea and/or individual genetic differences in the metabolism of pilocarpine. ${ }^{15,16}$

An additional limitation of this study is that the subjects were in a narrow age group preventing a meaningful assessment of the effect of age. However, previous clinical studies have shown that in older subjects pilocarpine can induce a greater accommodative response than anticipated from voluntary accommodation. ${ }^{8,17,18}$

\section{Conclusion}

To fully understand the mechanism of accommodation, it is important to accurately characterize the factors that limit accommodative amplitude. Since accommodation is effort based, recent studies may have underestimated the full accommodative amplitude in young subjects. ${ }^{2-5,13}$ In accommodative studies, this demonstrates the importance of training and encouraging subjects to try to focus on the nearest target before assuming maximum voluntary accommodation. ${ }^{19}$ In addition, the results of this study assist in defining limits for mathematical parametric studies. And for patients with accommodative spasm, the results of this study can give an estimation for the severity of the spasm.

\section{What was known}

- In young subjects, objectively measured voluntary and pilocarpine-stimulated accommodative amplitude was less than push-up-measured voluntary accommodative amplitude. ${ }^{13}$

- In young subjects, objectively measured accommodative amplitude peaks or plateaus at 8 diopters. ${ }^{4}$

\section{What this article adds}

- When objectively measured, pilocarpine-stimulated accommodative amplitude was greater than previously reported voluntary-stimulated accommodative amplitude for healthy subjects aged 19-24 years. ${ }^{2-5,13}$

- In healthy subjects aged 19-24 years old, objectively measured pilocarpine-stimulated accommodative amplitude was equal to or greater than reported push-up-measured voluntary accommodative amplitude., ${ }^{1,12}$ 
- In young subjects, the eye is capable of objectively accommodating significantly more than 8 diopters.

\section{Disclosure}

The authors report no conflicts of interest in this work.

\section{References}

1. Duane A. Normal values of the accommodation at all ages. JAMA. 1912; 59(12):1010-1013.

2. León A, Estrada JM, Rosenfield M. Age and the amplitude of accommodation measured using dynamic retinoscopy. Ophthalmic Physiol Opt. 2016;36(1):5-12.

3. Anderson HA, Stuebing KK. Subjective versus objective accommodative amplitude: preschool to presbyopia. Optom Vis Sci. 2014;91(11): 1290-1301.

4. Anderson HA, Hentz G, Glasser A, Stuebing KK, Manny RE. Minus-lens stimulated accommodative amplitude decreases sigmoidally with age: A study of objectively measured accommodative amplitudes from age 3 . Invest Ophthalmol Vis Sci. 2008;49(7):2919-2926.

5. Wold JE, Hu A, Chen S, Glasser A. Subjective and objective measurement of human accommodative amplitude. $J$ Cataract Refract Surg. 2003;29(10):1878-1888.

6. Esteve-Taboada JJ, Del Águila-Carrasco AJ, Bernal-Molina P, FerrerBlasco T, López-Gil N, Montés-Micó R. Effect of phenylephrine on the accommodative system. J Ophthalmol. 2016;2016:7968918.

7. Vilaseca M, Arjona M, Pujol J, Peris E, Martínez V. Non-cycloplegic spherical equivalent refraction in adults: comparison of the double-pass system, retinoscopy, subjective refraction and a table-mounted autorefractor. Int J Ophthalmol. 2013;6(5):618-625.

8. Berggren L. Individual responsiveness to topical pilocarpine and the effects of variations in application technique. Acta Ophthalmol. 1985;63(6):642-646.
9. Buehren T, Collins MJ, Loughridge J, Carney LG, Iskander DR. Corneal topography and accommodation. Cornea. 2003;22(4):311-316.

10. Sisó-Fuertes I, Domínguez-Vicent A, del Águila-Carrasco A, FerrerBlasco T, Montés-Micó R. Corneal changes with accommodation using dual Scheimpflug photography. J Cataract Refract Surg. 2015;41(5): 981-989.

11. Liu T, Thibos LN. Variation of axial and oblique astigmatism with accommodation across the visual field. $J$ Vis. 2017;17(3):24.

12. Hofstetter HW. A comparison of Duane's and Donder's tables of the amplitude of accommodation. Am J Optom Arch Am Acad Optom. 1944;21(9):345-362.

13. Ostrin LA, Glasser A. Accommodation measurements in prepresbyopic and presbyopic population. J Cataract Refract Surg. 2004;30(7): $1435-1444$.

14. Havener WH. Ocular Pharmacology. 4th ed. St Louis: C.V. Mosby; 1978:277.

15. Endo T, Ban M, Hirata K, Yamamoto A, Hara Y, Momose Y. Involvement of CYP2A6 in the formation of a novel metabolite, 3-hydroxypilocarpine, from pilocarpine in human liver microsomes. Drug Metab Dispos. 2007;35(3):476-483.

16. Hioki T, Fukami T, Nakajima M, Yokoi T. Human paraoxonase 1 is the enzyme responsible for pilocarpine hydrolysis. Drug Metab Dispos. 2011;39(8):1345-1352.

17. Abramson DH, Franzen LA, Coleman DJ. Pilocarpine in the presbyope Demonstration of an effect on the anterior chamber and lens thickness. Arch Ophthalmol. 1973;89(2):100-102.

18. Koeppl C, Findl O, Kriechbaum K, Drexler W. Comparison of pilocarpine-induced and stimulus-driven accommodation in phakic eyes. Exp Eye Res. 2005;80(6):795-800.

19. Provine RP, Enoch JM. On voluntary ocular accommodation. Precept Psychophys. 1975;17(2):209-212.
Clinical Ophthalmology

\section{Publish your work in this journal}

Clinical Ophthalmology is an international, peer-reviewed journal covering all subspecialties within ophthalmology. Key topics include: Optometry; Visual science; Pharmacology and drug therapy in eye diseases; Basic Sciences; Primary and Secondary eye care; Patient Safety and Quality of Care Improvements. This journal is indexed on

Submit your manuscript here: http://www.dovepress.com/clinical-ophthalmology-journal

\section{Dovepress}

PubMed Central and CAS, and is the official journal of The Society of Clinical Ophthalmology (SCO). The manuscript management system is completely online and includes a very quick and fair peer-review system, which is all easy to use. Visit http://www.dovepress.com/ testimonials.php to read real quotes from published authors. 